\title{
OPTIMIZATION STRATEGY OF DISTORTION RATE CONTROL FOR HIGH POWER TRANSFER SUPPLYING AN X-RAY TUBE
}

\author{
Rachedi Mohamed — Bourahla Mohamed *
}

\begin{abstract}
This paper mainly concerns a contribution in the art development of high power generator supplying an X-ray tube for medical use. A generic method is proposed to reduce thermal stresses induced in X-ray tube during successive doses. For such application resonant DC-DC converter should be required, which generate output voltage and load current strictly identical to reference signal accompanied with normalized power factor quality. Primordially an adequate structure active filter connected in parallel at load lover is used to adjust the input and out put current distortion rate. With fuzzy logic control strategy, out put characteristics in transient and steady state are integrally mastery. This robust control type permits successive and repetitive taken measurement of radiology.
\end{abstract}

K e y w o r d s: X-ray tube, DC-DC resonant converter, high frequency transformer, active filter, distortion rate, robust control

\section{INTRODUCTION}

Actually, high DC power supply, constitutes the source of development of certain key sectors, especially the health sector using medical imaging. Indeed, the equipment of these applications generally based on the structure of a DC-DC converter. The state of the art compact $\mathrm{X}$-ray high-power generating apparatuses using a constant HF PWM bridge inverter-linked DC-DC converters with parallel or series and parallel hybrid topology have positively begun to be advantageously introduced by the authors in order to radiate a high-quality stabilized X-ray power with a quicker dynamic response under a widely changed voltage regulation range over $20 \mathrm{kV}$ to $150 \mathrm{kV}$ [1]. An implementation method of electrical energy conversion is presented in order to realize high power supply for medical imaging equipment, conformably to technical and industrial norms. This specifically application requires the performance energy transfer that can be achieved only by the resonance. Method objective tend together all the factors that contribute to the development of optimizing for this supply type where compromise between the characteristics components is adopted.

Study provide significant results in controlling the stability voltage $\mathrm{X}$-rays tube stability, this investigations used performances of transformers high frequency high voltage $(\mathrm{HF} / \mathrm{HV})$ including its optimal non saturated state of magnetic circuit [2]. Tow important conditions has been taken in count for which the transformer losses are minimal: First one imposes that for every transformer kernel, there is a critical frequency and the second one, a flux density is selected lower than flux saturation density value.

A contribution is to realize the X-ray tube protection against over voltage induced when taken repeatedly and especially successive doses that generate an accumulated heat stress and causes destruction of X-ray tube. In order to realize low cost, more high-power density and improve better power conversion efficiency, a constant high frequency phase shifted PWM inverter using parallel resonant topology witch has been proposed. Optimum operating point of high frequency high voltage (HV/HF) transformer linked resonant DC-DC power converter is application condition. Resonant DC-DC power converter use the internal parasitic resonant circuit components (LR$\mathrm{CR}$ ) of $50 \mathrm{kHz}$ high-voltage transformer and its equivalent input capacitance of high voltage cable feeder as the dc output smoothing filter.

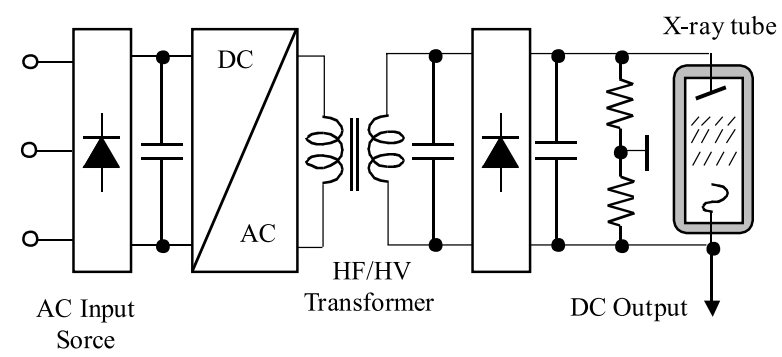

Fig. 1. Principal structure of X-ray power generator

\section{PRINCIPLES OF TECHNICAL MEDICAL RADIOLOGY}

With the increased static converters performance new fields application are open. Some of them are very demanding in terms of dynamic performance, particularly in medical imaging. X-ray tubes operate under high voltage supply where $\mathrm{X}$ rays emission is taken on. These are accelerated towards cathode X-ray tube by an electric field created by a differential high potential (typically 10

* Department Electrotechnics, Laboratory of Electrical Drives and Power Electronics, B.P 1505, El M'naour, USTO, Oran-Algeria, rachedi_mo@yahoo.fr 


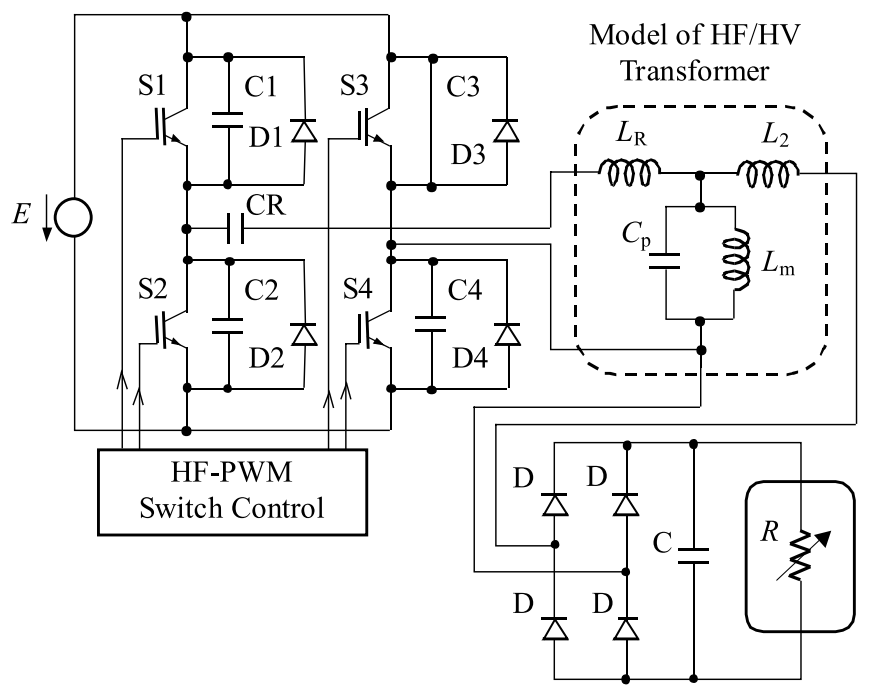

Fig. 2. Resonant DC-DC converter with equivalent circuit model of high-voltage HF transformer

to $150 \mathrm{kV}$ ) between the filament which serves as anode and cathode. Side anode is the target electrons and is used as the aria of liberation $\mathrm{X}$-rays. In medical radiology efficiency X-ray tube is very low around $1 \%$ and all energy rest is reflected into heat form [3]. The current used in the X-ray tube must be adjusted and transformed into a high-voltage current.

Figure 1 shows the principal assembling, intended for this power supply type. The three exposure parameters controlled by the operator are:

- Exciting anode current representing the amount of Xray products.

- Stabilizing DC High voltage to t high X-ray density project application.

- Exposure time (milliseconds) that represent radiation $\mathrm{X}$ amount.

\section{DC-DC CONVERTER STRUCTURE FOR CONDITIONING POWER CIRCUIT OF X-RAY GENERATOR USING RESONANT PWM INVERTER}

In order to realize low cost, more high-power and improve best quality power conversion efficiency and out put dynamic characteristics, a constant HF phase-shifted PWM inverter using parallel topology for X-ray power supply has been proposed and studded on the basic of new generation semiconductor devices for switching-mode power control [3].

A full-bridge high frequency PWM inverter linked parallel resonant switching-mode DC-DC converter topology with a phase-shifted PMW control scheme displayed in Fig. 2, witch is developed recently and is possibly applied for X-ray generating power supply both in order to minimize the switching losses and EMI noise level. This DC high voltage power supply consists of the voltage-fed parallel resonant inverter including series and parallel hybrid topology $50 \mathrm{kHz}$ high voltage transformer and $\mathrm{HF}$ diode rectifier with an equivalent input parasitic capacitor $(\mathrm{CP})$ existing in the high voltage feeding cable and the capacitance between each coil layer of the secondary windings in high voltage transformer.

To realize a semiconductors spontaneous switching, an oscillating circuit LR-CR (Fig. 2) including primary leakage inductance LR of the transformer and capacitor compensation CR should be used. It has opted for structure DC-DC converter the following assumptions:

- Proper terminals switches capacitors are including in capacitor compensation.

- The parasitic capacitor $C_{P}$ may contribute to the switching process of rectifier diodes.

- The resonant circuit $C_{R}-L_{R}$ contributes to the establishment of semiconductors switching between two successive commutations.

- Principal flux density of transformer is strictly less than saturation value [3].

The main power conversion circuit topology is based upon the full bridge PWM type parallel resonant inverter. A $50 \mathrm{kHz}$ AC high voltage produced by the ideal highvoltage transformer is rectified through diode rectifier and to feted X-ray tube connected to the high voltage cable whose in put capacitance can be effectively utilized as DC output smoothing capacitor.

\section{RESONANT DC-DC CONVERTER BEHAVIOR}

The X-ray tube power is smoothly regulated using its density current anode filament; witch is composed of the quasi-resonant switching mode single-ended DC-DC converter operating at the principle of zero-voltage switching or zero current switching [4]. The AC-DC power conversion is realized with series resonance inverter, represented by the following elements:

- Primary leakage inductance $L_{R}$ of transformer contributes in process resonance. 


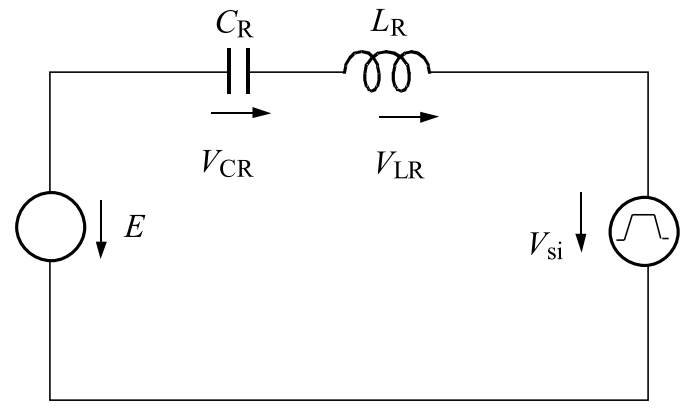

Fig. 3. Topology of the DC-DC converter operating in a sequences of stages (1) to (6), during one period $T$

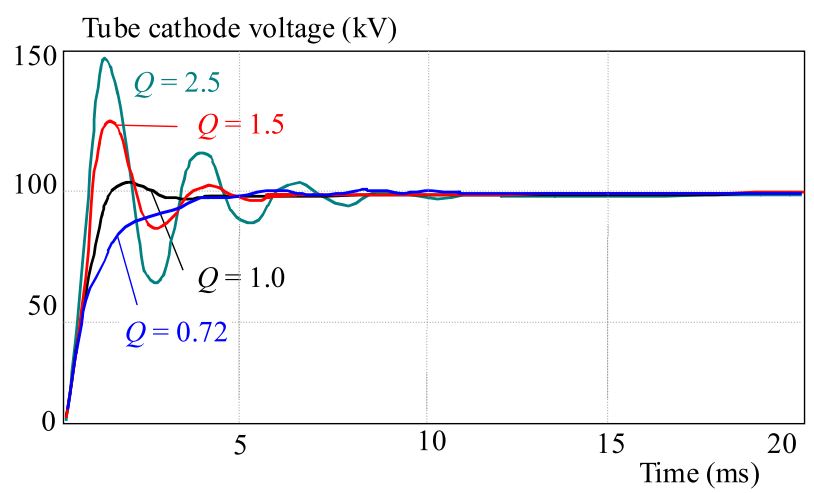

Fig. 4. Different loads out put characteristics with open loop system

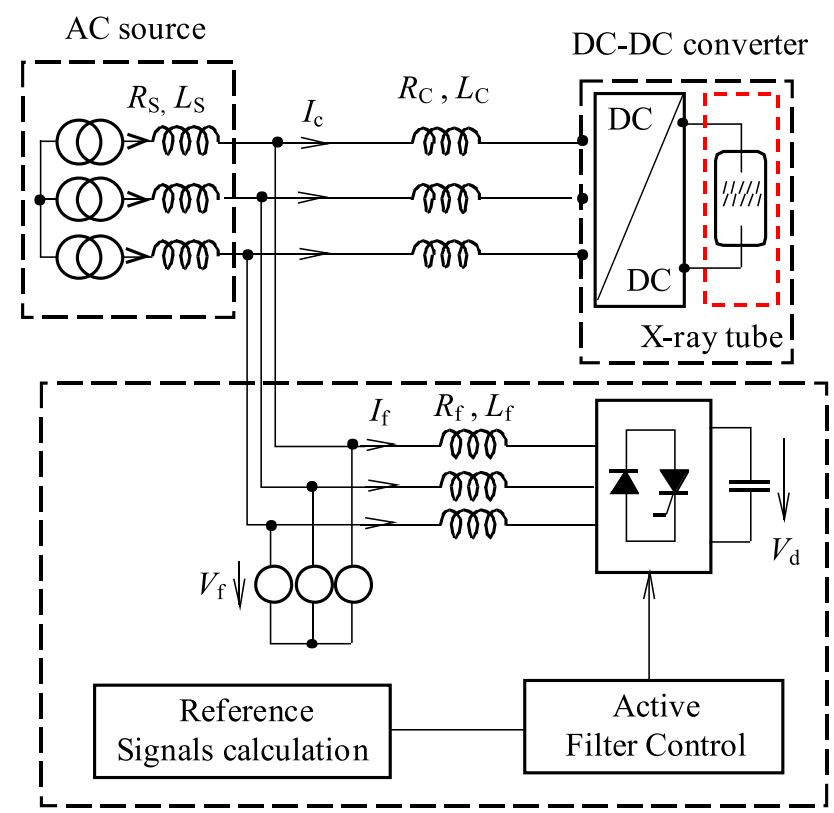

Fig. 5. Principal active filter structure type voltage connected in parallel with in put source

- The compensation capacitor $C_{R}$; including capacitor parasitic secondary windings and the high voltage feeding cable capacitor.

- With resonant circuit $L_{R}-C_{R}$, switching-mode of inverter modules interrupters can be operating at principal of zero current switching or zero voltage switching.

However, owing to the HF switching technology, the sufficient DC out put power can be obtained by using the series resonant witch is favorably obtained by the couple $L_{R}-C_{R}$. During one period $T$, operating sequences the topology of the DC-DC converter [2] using high frequency $(50 \mathrm{kHz})$ are illustrated in Fig.3.

Mainly considered mails contained voltage $V_{C R}, V_{L R}$ respectively of terminals $C_{R}$ and $L_{R}$ and also an X-ray tube output high voltage $V_{S}$. In the same way $i_{C}$ and $i_{L}$ represent current partners throwing $C_{R}$ and $L_{R}$. E is an instantaneous value of the battery source.

X-ray tube voltage $V_{s}$ formula of each operating mode (sequence topology) is respectively done by expressions

$$
\begin{aligned}
& \text { Stage } 1 ; 0 \leq t \leq T / 6: \\
& V_{S 1}=E-\left(V_{C R}+V_{L R}\right),
\end{aligned}
$$

Stages 2,$3 ; T / 6 \leq t \leq 3 T / 6$ :

$$
\begin{aligned}
& V_{S 2}=-E-\left(V_{C R}+V_{L R}\right), \\
& V_{S 3}=-E-\left(V_{C R}+V_{L R}\right),
\end{aligned}
$$

Stages $4,5,6 ; 3 T / 6 \leq t \leq T$ :

$$
\begin{aligned}
& V_{S 4}=-E+\left(V_{C R}+V_{L R}\right), \\
& V_{S 5}=-E+\left(V_{C R}+V_{L R}\right) \\
& V_{S 6}=-E+\left(V_{C R}+V_{L R}\right)
\end{aligned}
$$

with $V_{C R}=\left(1 / C_{R}\right) \int i_{C} \mathrm{~d} t$ and $V_{L R}=L_{R} \mathrm{~d} i / \mathrm{d} t$

$L_{R}$ and $C_{R}$ are respectively the inductor and capacitor series resonant circuit.

$(\mathrm{d} / \mathrm{d} t) V_{S 1}=(\mathrm{d} / \mathrm{d} t) E-\left(1 / C_{R}\right) i_{C}-L_{R}(\mathrm{~d} / \mathrm{d} t)^{2} i$,

$(\mathrm{d} / \mathrm{d} t) V_{S 2}=-(\mathrm{d} / \mathrm{d} t) E-\left(1 / C_{R}\right) i_{C}-L_{R}(\mathrm{~d} / \mathrm{d} t)^{2} i$,

$(\mathrm{d} / \mathrm{d} t) V_{S 3}=-(\mathrm{d} / \mathrm{d} t) E-\left(1 / C_{R}\right) i_{C}-L_{R}(\mathrm{~d} / \mathrm{d} t)^{2} i$,

$(\mathrm{d} / \mathrm{d} t) V_{S 4}=-(\mathrm{d} / \mathrm{d} t) E-\left(1 / C_{R}\right) i_{C}-L_{R}(\mathrm{~d} / \mathrm{d} t)^{2} i$,

$(\mathrm{d} / \mathrm{d} t) V_{S 5}=-(\mathrm{d} / \mathrm{d} t) E+\left(1 / C_{R}\right) i_{C}+L_{R}(\mathrm{~d} / \mathrm{d} t)^{2} i$,

$(\mathrm{d} / \mathrm{d} t) V_{S 6}=-(\mathrm{d} / \mathrm{d} t) E+\left(1 / C_{R}\right) i_{C}+L_{R}(\mathrm{~d} / \mathrm{d} t)^{2} i$. 

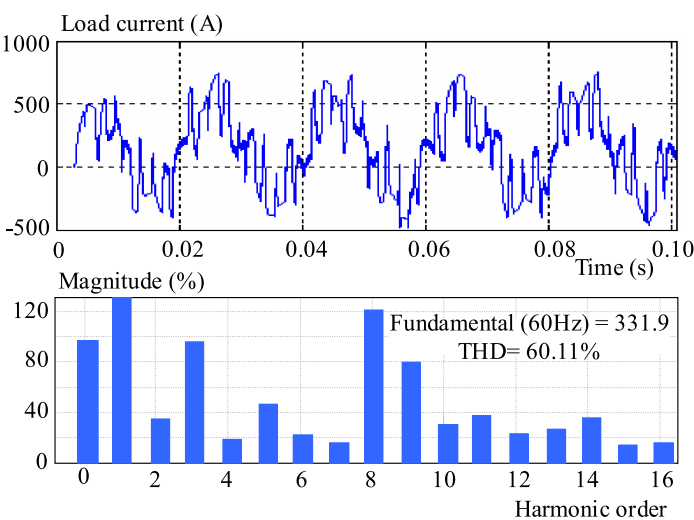

Fig. 6. Enter current wave forms before filtering
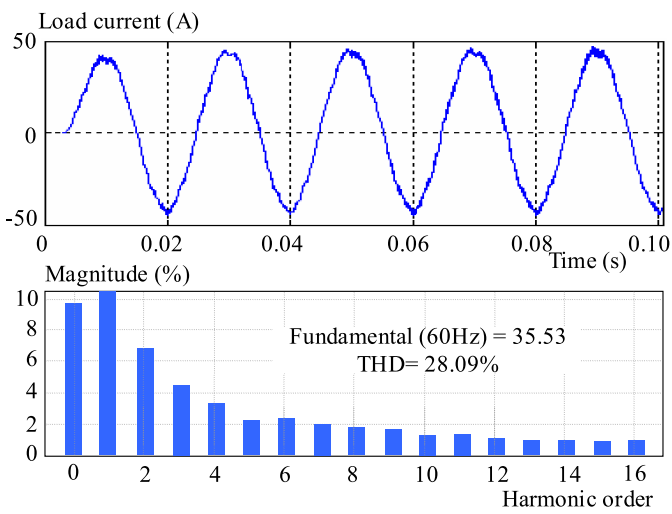

Fig. 8. Enter current wave forms after filtering

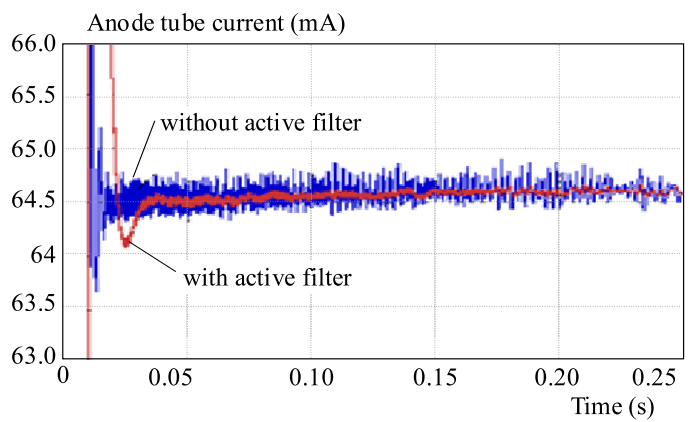

Fig. 10. Current filament wave forms using active filtering with low load

Formulas (7) to (12) governed behavior system process. Then solution of differentials equations describes characteristics system response witch illustrates the waves forms tube cathode voltage $V_{S}$ and anode current $I_{S}$ waves forms. By introducing the operator $p=\mathrm{d} / \mathrm{d} t$, the transfer functions $F_{i}(p),(i=1, \ldots 6)$ for each mode can be formulated as following:

$$
\begin{aligned}
& F_{1}=\left(p k /\left(p^{2}+2 \zeta w p+w^{2}\right),\right. \\
& F_{2}=-\left(p k /\left(p^{2}+2 \zeta w p+w^{2}\right),\right. \\
& F_{3}=-\left(p k /\left(p^{2}+2 \zeta w p+w^{2}\right),\right. \\
& F_{4}=\left(p k /\left(-p^{2}+2 \zeta w p-w^{2}\right),\right. \\
& F_{5}=\left(-p k /\left(p^{2}+2 \zeta w p-w^{2}\right),\right. \\
& F_{6}=\left(-p k /\left(p^{2}+2 \zeta w p-w^{2}\right) .\right.
\end{aligned}
$$
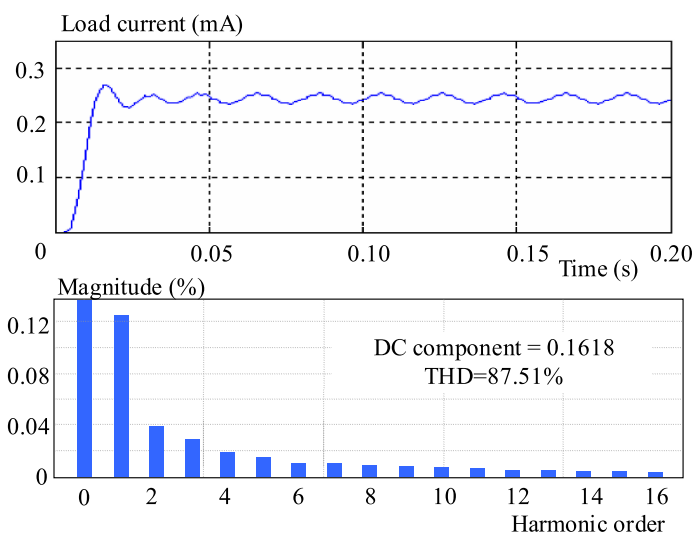

Fig. 7. Load current wave forms before filtering
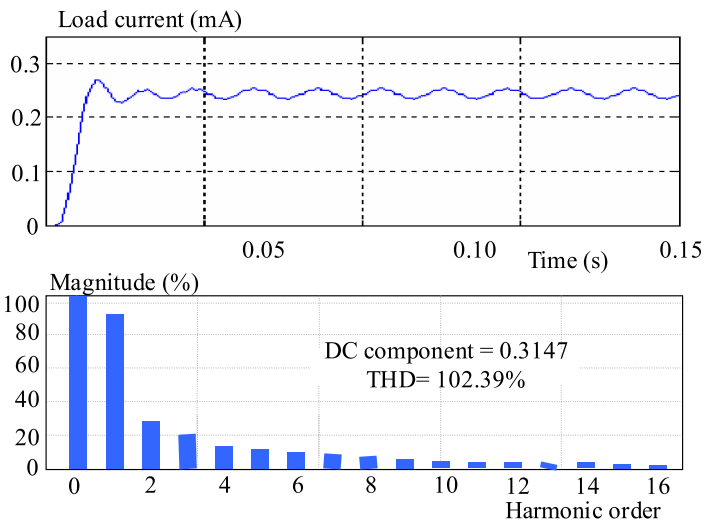

Fig. 9. Load current wave forms after filtering

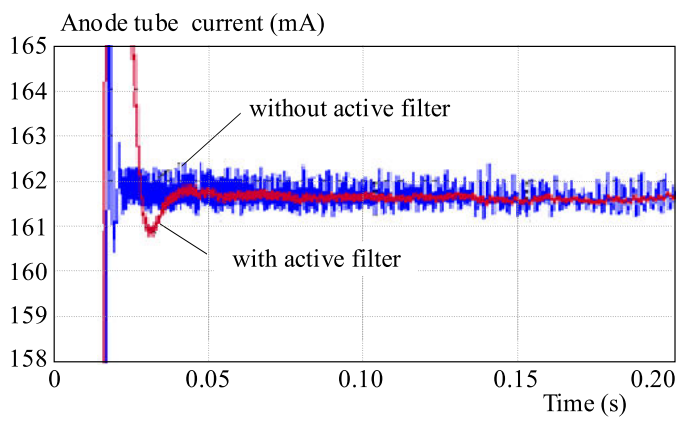

Fig. 11. Current filament wave forms using active filtering with heavy load

In order to simplify transfer functions forms next parameters are adopted:

- $w=1 /\left(L_{R} C_{R}\right)^{1 / 2}$, system pulsation.

- $2 \zeta=R\left(C_{R} / L_{R}\right)^{1 / 2}$, proper damping for load.

- $Z=2\left(L_{R} / C_{R}\right)^{1 / 2}$, impedance proper system.

- $k=R C_{R} w^{2}$, gain factor of system, $R$ load resistance.

Formulas (13) to (18) represents the responses in open loop voltage $V_{s}$ of the cathode $\mathrm{X}$ ray tube with load factor as expressed by: $Q=Z / R, Z$ is the characteristic impedance of the system. Generally, these responses are similar to those of a second order system in open loop as showed in Fig.4.

For a high damping (low factor quality $Q$ ), the output voltage $V_{s}$ presents over value during transient state (for low loads). These responses are devoid of qualifica- 


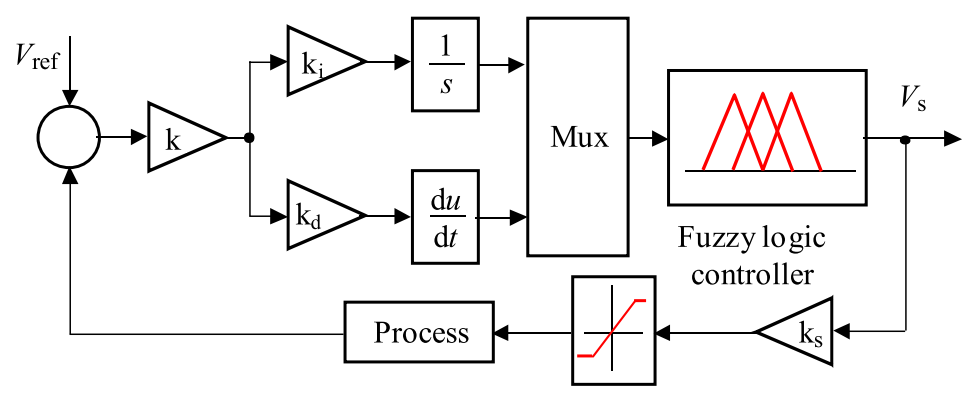

Fig. 12. Control system bloc diagram using fuzzy logic regulation

tions and are not recommended in medical imaging because this conventional supply type should be absolutely required to reduce extremely the delivered tube voltage ripple. The form of waves in Fig. 4 illustrates the followings undesirable characteristics:

- Cathode tube voltage ripples extremely undesirable.

- Intolerable over voltage, especially for high voltage taken.

- System response time considerably slow.

\section{POWER FACTOR AMELIORATION USING ACTIVE FILTERING CONTRIBUTION}

Power static converters induce harmonic pollution injected in external circuit. Witch causes Power factor quality degradation indeed; imposed reactive power compensation is ducted. This Paratactic study concerns a modern solution to eliminate integrally or partially superior rang harmonics order. For different conditions and objective many filter types are request:

- Remove pollution from the source to supply a sensible load (example of our application)

- Filtering polluted load to protect other receptors.

$\mathrm{X}$ ray-tube is the main sensible organ of medical imaging circuit equipment in side, anode current should be control as soon as possible. In this investigation structure of the voltage active filter is choose and connects in parallel with in put circuit source. The principal of the control active filter type voltage concerns harmonics identification method based on calculus of instantaneous active and reactive power witch permutes a best results to this application [10]. Figure 5 shows principal active filter structure type voltage, that comports controlled DC-AC inverter witch generates harmonics current and voltage with the same magnitude harmonic source rang but with opposite sign.

In order to appreciate active filter contribution firstly behavior system is analyzed without using filtering, so figures 6 and 7 illustrates high source in put current distortion rate $(\mathrm{THD}=60.11 \%$ ) however an undesirable out put load voltage and anode current contacted (THD $=87.51 \%$ ). In consequently, power factor degradation is caused by harmonics external circuit and the intrinsic harmonics of the proper system. This concludes the high power conditioning can not be realized for conventional supply medical imaging.

On the other hand, a favorable distortion rate of the in put source current is developed when installing parallel active filter and a sinusoidal current is obtained comparatively with the first case. Even, the source current presents high quality power factor ( $\mathrm{THD}=34.11 \%$ ) as shows in Fig. 8, in same time, Fig. 9 shows a best obtained quality of anode X-ray tube current ( THD $=28.09 \%$ ).

Figures 10 and 11 illustrate successively anode filament current in case of low load and current with heavy load. Consequents system control performances with adopted active filter can be obtained for width load game.

\section{STEADY STATE AND TRANSIENT OUTPUT CHARACTERISTICS}

In order to obtain high quality power factor and continues DC power density absorption, robust method control of tube cathode voltage and anode current in dynamic and static stat is imposed with association active parallel filtering type voltage. In this conventional practical type adjustment of load current power factor tacked very satisfied values. Mainly contribution to developer optimal high DC power supply consists to apply the technical fuzzy logic control witch overcome desirable responses operator [7]. Figure 12 describes basic process regulation conditioning by the follows DC-DC property:

- Optimal transformer operating point witch permuted basic behavior of linear system [7].

- Favorable input current power factor delivered by installing appropriates parallel active filter.

- X-ray tube load is assimilated to resistor witch is linearly proportional with temperature.

To analyse proposed regulation efficiency there are two ways to exanimate out put system stability, the first one is reduce in shorter time repetitive over-voltage witch causes X-ray tube destruction during transient state, the second one concerns elimination of steady state ripples and offers acceptable out put response rate distortion factor.

To realize these performances it has compared out put characteristics obtained by the PID regulator and those determined by fuzzy logic control. By using fuzzy logic 
Cathode tube voltage $(\mathrm{kV})$

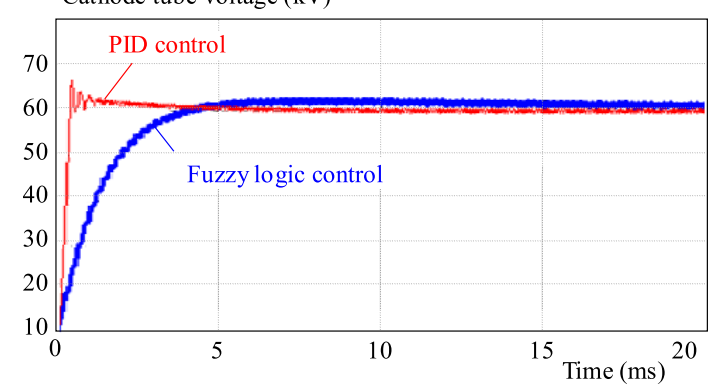

Fig. 13. Contribution PID and fuzzy logic control in dynamic and static stat for low load

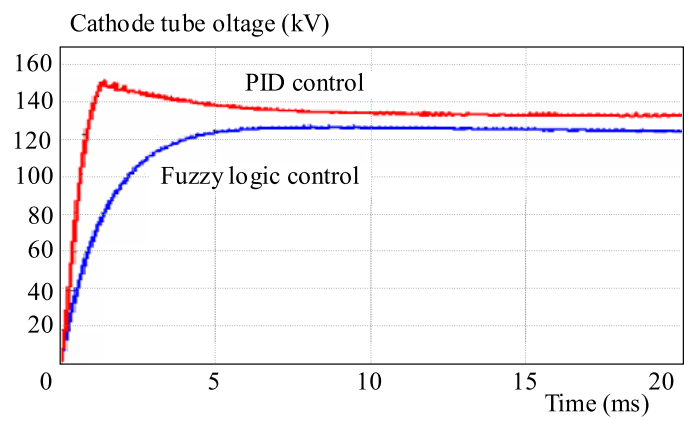

Fig. 15. Contribution PID and fuzzy logic control in dynamic and static stat for heavy load

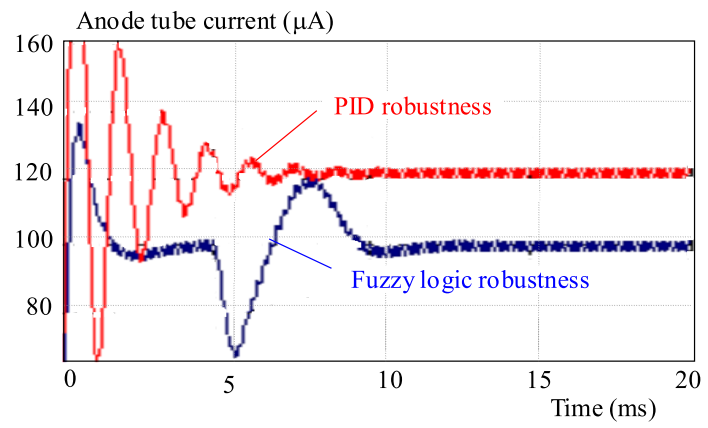

Fig. 17. Robustness face at disturbances injected into the system

controller, state transient side presents an exceptionally applied factor damping on the cathode voltage and anode current waves forms in comparison with results offered by the PID regulator as showed in figures 13 and 14 . In opposition, perfectly steady state with best Factor power quality is illustrated with PID controller (Fig. 15). Patricides values for this application; the power rating of $8 \mathrm{~kW}(80 \mathrm{kV} / 100 \mathrm{~mA}$, Fig.15), $12 \mathrm{~kW}$ (100 kV/120 mA, Fig.16) and $24 \mathrm{~kW}(150 \mathrm{kV} / 160 \mathrm{~mA}$, Fig.17). Generally, establishment transient state system is realized during 50 milliseconds however, energy quantity liberated inter Xray tube is admissible.

\section{PERFORMANCE AND ROBUSTNESS OF CONTROL SYSTEM}

The control system robustness against disturbances injected in system during the state dynamic is confirmed by

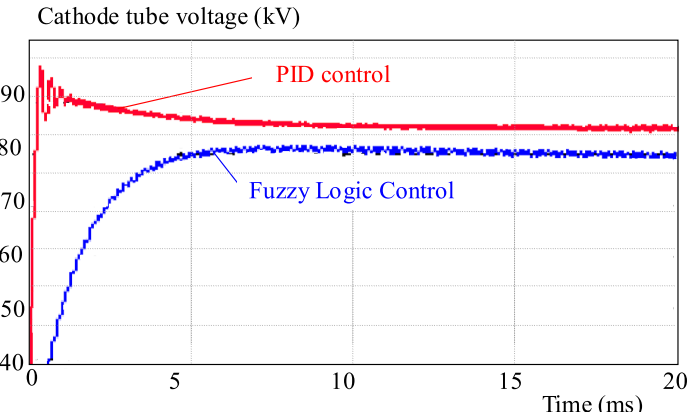

Fig. 14. Contribution PID and fuzzy logic control in dynamic and static stat for medium load

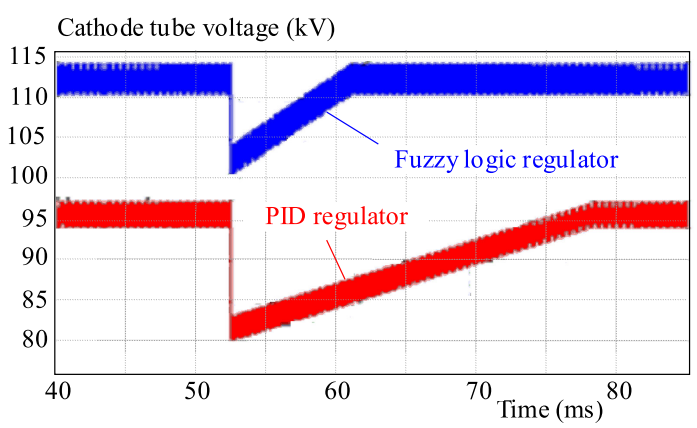

Fig. 16. Contribution PID control and fuzzy logic in dynamic and static stat for heavy load

examining strictly alignment of out put system response with reference signal during very short time. Figures 16 and 17 shows the waves form output voltage and current fitted disturbances injected in lover and downstream system when disturbances are rapidly rejected. With fuzzy logic control, the output signal degradation is less significant in comparison with the classical case of PID that suggests a low signal with noise.

The fuzzy logic strategy presents ability to restore the system order during in a short time. In this investigation strong contribution and qualification of active filtering is provided, in effect, improving the load current power factor allows large flexibility in system control.

\section{CONCLUSION}

The quality of the image is very much dependent firstly on the high direct voltage supply and secondly on the control technique used. A control method applied to the cathode tube X-ray voltage is presented with including active filtering connected in parallel with source. This control technique is should be robust under external disturbances and the controlled system parameter variations.

The accumulated thermal stresses induced in the $\mathrm{X}$ ray tube during successive doses contributes to reducing the tube life span. However, to reduce thermal effects on the X-ray tube must soften the over-voltage cathode tube during the dynamic system state. We can say, the process control in discrete system offers better performances, especially in the static system. 
The contribution is to realize the X-ray tube protection against over voltage induced when taken repeatedly and especially successive doses that generate heat stress accumulated, which can destroy the X-ray tube. In this context, we conducted an active filter placed in lover of the load (DC-DC converter), to increase the quality of the power factor of the source and it has been applied a more robust controller cons overruns tube voltage during transients. Hence, power transfer is mainly conducted by two certain characteristics; optimal operating point of the transformer and appropriates parallel active filter. Hence, control strategy is associated to the system in order to realize an ideal power factor quality of X-ray tube cathode voltage and anode current. This study contributes to developer practice method in controlling high power stability then adjusts the thermal stresses induced in the $\mathrm{X}$-ray tube.

\section{REFERENCES}

[1] SUN, J.-NISHIMURA, T.-NAKAOKA, M.: Resonnant Mode PWM dc-dc Converter with a High Voltage Transformer Link and its Control Methods for Medical Use X-Ray Power Supply, EPE Lausanne 7 (Aug 1999), 514-521.

[2] CARLOS, J.-CANESIN, A.-BARBI, I. : Novel ZCS PWM Converters, Transaction on Industrial Electronics 3 (March 1997), 1242-1258.

[3] ANGEL, M.-GARCIA, P.-BLANC, J. : Design Criteria for Transformers in High Voltage Output, High Frequency Power Applications, EPE 5 (Jun 1994), 125-132.

[4] BOURAhlA, M. : Contribution to the Opening of the GTO with a New Technique, Doctorat, Dept. Elect. Eng, U.S.T.O, 1993, University Oran, in Algeria.

[5] RACHEDI, M.-BOURAHLA, M. : Adaptation of Radiological Supply HV/HF for Medical Use, International Review of Physics (IREPHY) 3 No. 3 (Jun 2009), 131-139.

[6] IGHIL, T.-TIAN, B.-MATT, X.-GLAIZE, C.: A New Method to Eliminate the Effects of the High Voltage Transformer Parasitic Elements in a Static Resonant Supply, EPE 1 (1991).

[7] RACHEDI, M. : Supply DC-DC High Voltage, High Frequency for Medical Application; Simulation and Study, Magisterial, Dept. Elect. Eng. U.S.T.O University, 2002, Oran, Algeria.

[8] GUfFon, S.-SARINAnA, A.-BACHA, S.: Sliding Mode Control for Active Filtering with Improvement of the High Frequency Range Spectrum, In: Proceedings EuroPE 99 International Conference on Power Electric, 7-9 September 1999, Lausanne, Switzerland.
[9] Cheron, Y.-FOCH, V.-SALESSES, J. : Study of a Resonant Converter using Power Transistors in $25 \mathrm{~kW}$ X-Ray Tube Power Supply, Power Electronics Specialists, ESA, Proceedings, IEEE 5 (1985), 295-306.

10] GERARD, W.-WOLFE, H.-BRESLIN, J. : Optimised Transformer Design: Inclusive of HighFrequency Effect, Transaction on Industrial Electronics 2 (1998), 112-123.

11] BOURAHLA, M.-MAZARI, B.: The Switching Losses in Power Devices, In: Proceedings of Middle East Conference of Power Electronic, Giza, Egypt, Apr 1994, pp. 150-162.

12] BOURAHLA, M.-GLAIZE, C.: Investigation on Forced-Commutated GTO-Thyristors: The Mixed Turn-Off Thyristors, EPE, L.E.M France European, Montpellier, France, 1989.

13] YVON, C.: The Soft Commutation in the Conversion of Static Electricity, Lavoisier, Technical and Documentation, 1989.

14] LABRique, F.-SEGuiER, G.-BAUsiere, R. : Les Convertisseurs de l'Electronique de Puissance: La Conversion Continu-Alternatif, Lavoisier, Tome 4 TEC \& DOC, 1995.

Received 27 March 2011

Rachedi Mohamed, born in 1966 in Youb (w) Saïda, Algeria. Graduated from the Faculty of Electrical Engineering at the Bel-Abbes University of Technology in 1991 and took the position of assistant lecturer with the Department of Electro technical Electrical of Saida University. In the same year he took the position head of technical service in the business of servicing works and electric lighting 1991-1992. In 2002 received his Master in the researches field of Electrical Power Engineering and control, in 2003, was appointed Associate Assistant Master from 2005 he is graduated Assistant Master Class A. He was the President of the pedagogical Committee of the Faculty of Electrical Engineering in Saida (2005- 2007. He is attached to the laboratory control and optimization of electric drives, electrical engineering USTO, 2002. Assisted in many international's publications and conference. Currently, he prepares his doctorate in the field of X-ray tube supply development and high power conditioning for medical use.

Bourahla Mohamed graduated from the Faculty of Electrical Engineering and technology at the Montpelier-France University of Technology (Master) in 1989, in the same year he took the position of assistant lecturer with the Department of Electrical Power Engineering of USTO, Oran, Algeria. In 1991, he received his Doctorate in the field of Electrical Power Engineering at Department Electrotechnics. He has achieved his professorate 2006. At present is working on Electrical Drives and Power Electronics research and responsible for the coaching post graduation in USTO, Oran, Algeria. 